\title{
MATRIA, Devenir-Mujer, Devenir-Travesti o la PATRIA INVERTIDA DE ANTONIO SILVA
}

\author{
Biviana Hernández**
}

\section{Resumen}

Cómo se construye la subjetividad de un devenir-mujer y travesti, es la pregunta que en este artículo orienta la indagación de la obra poética de Antonio Silva (1970-2012), siguiendo la premisa del "devenir minoritario" que representan en ella los grupos excluidos del proyecto de nación moderno del Chile post-transición. El análisis se enfoca en la noción de devenir como un espacio crítico de verbalización de la otredad en que distintas voces y posiciones ideológicas (mujeres, prostitutas, indígenas, travestis) ingresan a los textos para manifestar su diferencia desde los márgenes territoriales y políticos trazados por el dispositivo social. Palabras clave: Antonio Silva, travestismo, devenir-mujer, marginalidad, otredad.

\section{MATRIA, Becoming-Female, Becoming-Travesti or THE INVERTED FATHERLAND OF ANTONIO SILVA}

\begin{abstract}
How textuality of a becoming-female and travesti is built, is the question in this article guides the inquiry into Matria (2007), of the Chilean poet Antonio Silva (1970-2012), following the premise of "minority becoming" that representing the groups excluded of the modern nation project of post-transitional Chile. We will focus on the notion of becoming a critical area of verbalization of otherness, where various voices and ideological positions (women, prostitutes, indigenous, transvestites) enter the text to express their difference from the territorial and political edge that in Matria constructs the subjectivity of peripheral and marginal subject.
\end{abstract}

Keywords: Antonio Silva, travestism, becoming-female, marginality, otherness.

Recibido: 09-07-2014

Aceptado: 09-01-2015

* Este artículo forma parte del proyecto FONDECYT de Postdoctorado No. 3130628: "Poesía y neovanguardia: textualidades para un nuevo repertorio", del cual soy investigadora responsable.

** Chilena. Doctora en Ciencias Humanas por la Universidad Austral de Chile, Facultad de Filosofía y Humanidades, Valdivia, Chile. Docente de la Facultad de Pedagogía de la Universidad Academia de Humanismo Cristiano e Investigadora postdoctoral de la Facultad de Letras, de la Pontificia Universidad Católica de Chile. biviana.hernandezz@gmail.com 
Escribe el nombre que te dio la patria; Aquella vocal bastarda -piel lodo ayesY bella

decapita

el nombre de tu Padre.

A.S.

\section{Antonio Silva: un poeta de los 90}

Partamos por una hipótesis generacional: en los poetas del $90^{1}$, "la sintomatología del desastre" (Sepúlveda 2013: 159) se habría apoderado de sus referentes y lenguajes producto de una "subjetividad postmoderna" que crearía personajes erráticos, "que deambulan como fantasmas en un afuera que los hace "náufragos" y marginales ante el vacío de los cambios" (Nómez 35). La tesis fue propuesta por Javier Bello, integrante de esta promoción, en 1995 (y difundida en el sitio web de la Universidad de Chile en 1998), y desde ahí ha sido utilizada y releída por la crítica literaria para aproximarse a las poéticas de los jóvenes escritores de las últimas décadas del siglo XX y comienzos del XXI.

La figura del "náufrago" en la poesía chilena reciente ha resultado un signo-símbolo para la promoción del $90^{2}$, y como tal ha servido para describir las características de un sujeto poético errante, sin territorio que ocupar y nombrar, un flanêur que deambula sin rumbo fijo por los espacios-despojos del capitalismo avanzado del Chile de la postransición, y cuyo fracaso como proyecto político habría determinado en él un profundo sentimiento de extravío territorial y existencial. Al respecto, afirma Magda Sepúlveda: “Como la Transición, los poetas de los 90 ocupan el lugar del hueco y eso los define. (...) Son los nuevos ciudadanos, sin tiempo, sin historia, caracterizados sólo por fragmentos que son comparados a los restos de la despensa de una casa abandonada"

1 Integran esta promoción de poetas, Javier Bello, Andrés Anwandter, Germán Carrasco, Verónica Jiménez, Alejandra del Río, Antonia Torres, Gustavo Barrera, Marcelo Pellegrini, David Preiss, Rafael Rubio, Damsi Figueroa, Leonardo Sanhueza, Yanko González, Pedro Montealegre, Jaime Huenún, Rafael Rubio, Matías Sepúlveda, Christián Formoso, David Bustos, Enoc Muñoz, Adán Méndez, Kurt Folch, entre los principales.

2 Esta figura está muy presente en el imaginario marítimo de una de las poetas más interesantes de los 90, Verónica Jiménez. Véase, por ejemplo, "La derrota del mar" de su primer poemario, Islas flotantes: "nosotros que algún día soñamos en lechos / extensos como las velas de los barcos / y construimos un hogar sobre el viaje de las aguas / bendecidos por la música del mar en la noche / andamos ahora en esta oscura rada / como náufragos arrojados a su mala suerte / vomitando espuma / con los pies enterrados en la arena / y la piel herida por la sal" (28). 
(159). En este escenario, y dentro de una gran variedad de registros, un núcleo poético que surge alrededor del 2000 (Espinosa 2006), vuelve a privilegiar el desencanto, aunque no de manera violenta sino más bien irónica y hasta cínica: "Hay ausencia de metarrelatos y se desmenuza la pequeña tragedia de lo cotidiano, se recupera la barriada, la población marginal y se instala la trayectoria nómade. Se desmitifica de nuevo la figura del poeta y el rol que cumple la poesía." (Nómez 2012: 35-36).

Desencanto, catástrofe, extravío, desconcierto, ruina, fantasmagoría, ironía, apatía, cinismo, son algunos de los apelativos que condensa el repertorio poético de los autores reunidos bajo la estela de la promoción del 90, ya sea que se los convoque por año de nacimiento, estéticas o filiaciones ideológicas comunes o porque tal vez todas ellas deslindan en la "heterotopía" en tanto enclave de representación espacial (y ya no temporal como en la utopía moderna) para nombrar y simbolizar este escenario de catástrofes y naufragios, que estará marcado por la caída del horizonte utópico, a nivel global, como por los ideales de emancipación y justicia sociales que dejaría, como producto y consecuencia, la implantación y consolidación del modelo neoliberal en Chile después de diecisiete años de dictadura militar, y el supuesto retorno a la democracia, en el así llamado periodo de la Transición a partir de 1990. Muchos de los textos escritos por los náufragos sostienen la premisa de que este periodo no ha terminado, incluso hasta la primera década del 2000, como advierte Sepúlveda, siendo esta una de las causas por las cuales la Transición llegaría a convertirse en un signo ideológico para esta promoción, conforme la voz de un "testigo imposible", un sujeto que insiste en remitirse al pasado a fin de rearticular la historia y la memoria social a partir de sus fragmentos dispersos:

Al elaborar el desastre, la voz proporciona sucesos y objetos, al modo de un arqueólogo, que permiten armar el rompecabezas de la historia. Y puede recordar un pasado más remoto que la herida, donde la calle era habitada y la población era el resultado de una movilización urbana. Los que hablan en estos poemas (...), no tienen territorio, pero están acercándose al puerto bajo la convicción de que al zurcir el tejido social volverá la ciudad. (174-5).

En la poesía de Antonio Silva (1972-2012)³, no obstante, no hay mar ni puerto al que arribar. Tampoco la intención reparadora de la historia o del 
tejido social. La ruina es parte de una herida primordial, anterior incluso a la historia, que está marcada a pulso y a fuego por una marginalidad de triple naturaleza: étnica, social y sexual. Una ruina-herida que en la voz poética de Silva va a determinar la naturaleza de un sujeto "otro" como una marca vital de/desde el propio nacimiento. Y si bien su obra no ha sido incluida o analizada a partir de las características de esta promoción, su poética bien se instala en las figuraciones de la heterotopía como un topos sensible de la experiencia estética, vital y social, que marca los pasos perdidos de un sujeto huérfano y autoexiliado hacia la recuperación de la memoria histórica, cuyo origen el poeta va a situar en el "encuentro" del viejo con el nuevo mundo.

Una constante en sus tres libros de poesía, es la figuración de la ruina a partir del dislocamiento de la vida personal y colectiva producto de la "violencia fundacional" de un nuevo continente, primero, y los circuitos globalizados del consumo y el poder neoliberal, luego, durante la Transición. Como los poetas de origen mapuche, Elicura Chihuailaf, Jaime Huenún, Leonel Lienlaf, o autores más jóvenes de las promociones más recientes, como David Aniñir, que, en tanto resistencia y reivindicación de su origen étnico-cultural, buscan interferir desde la escritura poética en la institucionalidad y hegemonía de la lengua oficial de Chile, el castellano, Silva introduce la voz del mapudungun mediante la variación lingüística del habla "mapuñol" -así como del spanglish- para movilizar un imaginario intercultural y apelar desde allí a un colectivo de reconocimiento y pertenencia minoritario ${ }^{4}$. $Y$ es en este punto donde la obra de Silva establece importantes conexiones con las poéticas de algunos de los "novísimos" del 2000 (Pablo Paredes, Diego Ramírez, Felipe Ruiz o Héctor Hernández), poetas que, en opinión de Sepúlveda, evidencian la noción de crisis del Estado chileno al elaborar utopías territoriales a partir de la libertad sexual y la movilidad social

3 Conforman su obra tres libros de poesía: Matria (2007), Analfabeta (2000) y Andrógino (1996). Este último ganador del Concurso de Literatura Eusebio Lillo de la Municipalidad de El Bosque, comuna de Santiago, en 1996. Los tres se encuentran reunidos, a tres años de su muerte, en la reciente compilación, a cargo de Héctor Hernández Montecinos, El imperio de los sentimientos: Obra reunida (Cuarto Propio, 2015).

4 Lo que define a una minoría no es el número. De allí entiendo el vocativo en el sentido de "minoritario" no solo como un dato estadístico, sino como "las relaciones internas con el número", cuando una minoría "puede ser numerosa o incluso infinita; e igual ocurre con una mayoría" (Deleuze y Guattari 2010: 473). Considero también el sentido que a partir de esta definición propone Néstor Perlongher en la noción de devenir-minoritario: “Mayoría y minoría no entendidas por cálculo cuantitativo, sino en tanto calidad de dominación: determinación de un patrón a partir del cual se miden las diferencias; se trataría, en otras palabras, de un modo dominante de subjetivación $(68-9)$. 
de sus búsquedas y preferencias. Utopías en las que se urde un sentido de protesta y disidencia cuando los poetas hacen coincidir su biografía personal con la de ciertos grupos y comunidades étnicas o tribus andróginas, excluidas del Chile postdictadura, y que se reconocen fuera de la nación hegemónica (240).

\section{Marginalidad y desecho neobarroco}

En un breve recorrido por los dos primeros libros de Antonio Silva: Andrógino (1996) y Analfabeta (2000), la trayectoria nómada del sujeto poético puede detectarse en el signo invertido del nombre propio femenino Alicia, por el patronímico masculino, Alicio con que se busca representar una identidad autoconstruida. ALICIO: "llevo cientos de años / Alicio en el país de las pesadillas" (11). La desolación, la pérdida, la soledad que todo lo invade: "Todos mis parientes me visitan para el día de los muertos" (11). En Andrógino, el hablante del Silva es un ser fantasmal que desde el laconismo de un canto lárico en agonía, en el charco de la urbe posmoderna, articula la forma de una memoria como paisaje y revelación: "He leído/en las hojas de los árboles/un poema de Dios/(...)/La mirada de un pájaro/perturbando el silencio/el silbido de la muerta/soplando los álamos" (15); "antes el aroma de un huerto/ grosellas y manzanas" (29); "Yo confundido/bajo silenciosos ciruelos" (30). Pero también como un decir carnal y sexual donde se inscribe la voz otra del sujeto: femenino, invertido, transgénero: "Soy la virgen que aparece/de vez en cuando/Soy la niña silbando/al final del cementerio/La mal nacida me decían/la solitaria y la loca/porque a veces lloraba/al leer poesía" (17), confiesa la voz feminizada del hablante en "Virgin", haciendo explícita su condición de "existencia contra natura", esto es, una ficción normativa donde "lo que se 'es', es lo que condena a no ser" (Giorgi 2004: 19). Una ficción normativa que en Silva se hará cuerpo e identidad cuando "la virgen", "la niña", "la mal nacida", "la solitaria y la loca" se reapropia y diversifica no solo en el lenguaje sino también en las prácticas sexuales y sociales que irán configurando una representación social y un "régimen de cuerpos" (19).

Rápidamente, la solitaria y la loca ${ }^{5}$ de Andrógino va a devenir la "analfabeta" de su libro homónimo como otra simbolización de lo minoritario, otra forma de autorrepresentarse en tanto que sujeto 
excluido y marginal, un cuerpo extraño a la vida colectiva y al régimen de la heteronormatividad ${ }^{6}$.

En el poema "Balada" de Gabriela Mistral el sujeto encuentra una forma de asumir su alteridad. En tanto reescritura de la Nobel chilena, Silva intenta formular una identidad heterotópica desde la cual autoafirmarse en la condición minoritaria de su yo poético. Recordemos el poema de Mistral:

Él pasó con otra; yo le vi pasar.

Siempre dulce el viento

y el camino en paz.

¡Y estos ojos míseros

le vieron pasar!

Él va amando a otra

por la tierra en flor.

Ha abierto el espino;

pasa una canción.

¡Y él va amando a otra

por la tierra en flor!

El besó a la otra

a orillas del mar;

resbaló en las olas

la luna de azahar.

¡Y no untó mi sangre

la extensión del mar!

El irá con otra

por la eternidad.

Habrá cielos dulces.

(Dios quiera callar.)

5 Con Sandra Garabano (2003), suscribo el uso del vocativo "loca" como una manera de inscribir la diferencia racial y de clase, además de la diferencia sexual, no solo desde una reevaluación de lo marginal, sino también desde un reordenamiento de las políticas de género dentro del mapa cultural de la globalización.

6 Para Gabriel Giorgi, "heteronormatividad" designa una gramática de lo social en tanto conjunto de discursos y de prácticas que postulan de manera normativa la heterosexualidad como la sexualidad con la cual se identifica el futuro de la nación y de la sociedad (56). Siguiendo los planteamientos de Berlant y Warner, sostiene que la heteronormatividad refiere una constelación de prácticas "que disemina en diferentes instancias el privilegio heterosexual como una marca tácita, pero central y organizadora, de la pertenencia social" (42). 
¡Y él irá con otra

por la eternidad! (144).

La mención, por cierto, no es gratuita. Silva transforma los celos y el amor no correspondidos de la hablante mistraliana en un símbolo kitsch del sentimentalismo naif del estereotipo mujer ${ }^{7}$ con el que polemiza su poema "MONITOR". Desde el gesto programático y persuasivo de un manifiesto estético-político, el poema de Silva opera como una lapidaria declaración de principios sobre las colectividades minoritarias y los grupos transgénero, en el contexto de esa ficción normativa del cuerpo homoerótico sobre el que se ejercen modos específicos de violencia. Veamos la versión resemantizada de Silva:

Traigo discurso débil; el secreteo de colegialas, el orgasmo con el compañero de curso a quien nadie tocó Traigo amor postizo; dentadura C.N.I.; la avaricia del poeta Bajo la pezuña del diablo los afeminados tartamudean

\section{Con lengua erecta}

Los boletines fascistas se aglutinan en mi correo

"Él se fue con otra yo le vi pasar"

Micrófono en mano serpentea Mistral

La poesía no se escribe. Se dispara (Analfabeta 30).

Decidor es el verso final de "MONITOR" para pensar la configuración de un arte poética. Si la poesía no se escribe sino que se dispara, tal vez haya que entender la afirmación como una arenga o proclama del propio "activismo" que modula y postula la escritura del autor. No olvidemos, en este sentido, que "monitor" remite a la persona que tiene por oficio enseñar, instruir, guiar o conducir una actividad en algún dominio

7 Estereotipo que Silva desplaza o contradice en la representación de las actividades más cotidianas atribuidas a las labores femeninas: la cocina, por ejemplo, no como el lugar por excelencia de la mujer que prepara los alimentos para el núcleo familiar, sino como escenario donde la hablante devenida mujer reflexiona sobre la condición de dominación y abuso que padecen los colectivos étnicos, sociales y sexuales marginados: "Hoy me afano en la cocina del horror/ollas y trastos iridizan lengua violada en el arete de la / realidad / De cuajo al mar hirviente / del orgasmo toda la sal toda/condimentos presas arqueadas por hielo de mi canción/fulgurante machete/todo a presión" (“DOMÉSTICA" 16). 
específico ya sea de la cultura, el deporte u otros campos ${ }^{8}$. No obstante, en el poema el sujeto enumera un estado de cosas que cifran una situación de violencia social: "discurso débil", "secreto", "orgasmo", "amor postizo", "dentadura C.N.I", "boletines fascistas". Contra ese estado de cosas, el sujeto emite una incisiva declaración de principios que busca llamar la atención, pero sobre todo llamar a la acción (¿política?) mediante el acto performático de travestimiento de la voz y del nombre propio; impostar, enmascarar, tartamudear, son las isotopías del poema donde se enfatiza una agencia de género: hablar como mujer, feminizando y sexualizando la escritura. El poema también plantea la configuración, en tanto arte poética, de una poesía que antes de la voz propia, única e intransferible de un autor, se articula a la base de una serie de otras voces de la ciudad letrada y la biblioteca personal del autor (como en este caso, Mistral). Él es su "monitor", el que "enseña" a la maestra pero en sus propias palabras; las palabras de un lenguaje homoerótico e intercultural.

Qué "dispara" entonces, la poesía de Silva: voces, posiciones, dinámicas, tensiones, figuras y simbolizaciones de la alteridad: mujeres, prostitutas, campesinas, proletarios, estudiantes, travestis, indígenas; personajes desviados de la heteronorma, anómalos o anormales, que Silva utiliza para elaborar un discurso y un imaginario sobre los procesos de mestizaje y aculturación que operan a través de prácticas lingüísticas como la diglosia, el murmullo, el tartamudeo o la afasia, "sonoridades escuetas", que en la concepción de Nicolás Rosa remiten a una forma abyecta de la ideología, a "una cierta intolerancia que se enmascara en la paciencia o en la indocilidad de un discurso; o, más aún, en la indolencia de un decir, que en este caso aflora (...) en un discurso nostálgico o quizá en una oculta queja melancólica" (1992: 59). Procesos que operan mediante la representación de cuerpos limítrofes entre lo legítimo y lo ilegítimo, entre la pertenencia y la diáspora, entre la identidad y la diferencia, entre la muerte social y la muerte física, entre el cuerpo orgánico y la cultura, entre la vida biológica y la vida política, entre 'ser' y 'hacerse' (Giorgi 20). Cuerpos violentados, en suma, que no se ajustan

8 La RAE ofrece otras interesantes acepciones de la entrada "Monitor", referidas sobre todo a la condición subalterna del sujeto que realiza esta actividad: a) Hombre que amonesta o avisa; b) En el Ejército, ayudante de los profesores de educación física; c) Subalterno que acompañaba en el foro al orador romano, para recordarle y presentarle los documentos y objetos de que debía servirse en su peroración; y d) Esclavo que acompañaba a su señor en las calles para recordarle los nombres de las personas a quienes iba encontrando. Consultado on line: http: / buscon.rae.es/drae/ 
a la inscripción social del cuerpo en la cultura y que terminan, por ello, siendo metáfora de un solo cuerpo contra-natura intervenido, el cuerpo histórico y colectivo de la comunidad étnica, de género y de clase de una lengua-ciudad-patria diezmada:

Soy un cuerpo intervenido por el desprecio aún así tengo neumas que marchitan el destino de la voz (...) un idioma domesticado para la castración Tengo una vocal escondida para silbar el día de tu muerte (...)

Yo la analfabeta, la precolombina del amor (Analfabeta 15).

En síntesis: desde la figura del andrógino de su primer poemario, a la analfabeta del segundo, que desterritorializa el habla como centro de poder para nombrar la patria, el territorio, el cuerpo, el sujeto despatriado de Antonio Silva va a asumir en Matria (2007) la "lengua diezmada" de Analfabeta como lugar de resistencia a ese idioma "domesticado para la castración"; proponiendo su contraparte, la lengua mapuñol como restauradora de los vínculos afectivo-simbólicos de esta comunidad de raros, todo un universo humano desposeído por la impronta de la "herencia colonial" 9 que lo atraviesa en sus distintos modos de agenciamiento estético y político.

\section{De la analfabeta a la india travestida de selva lírica}

Matria, el tercer y último libro publicado en vida de Antonio Silva se compone de seis secciones no numeradas: la primera, sin título, y la última, correspondiente a una cita de Jean Genet: "Poner a cubierto todas la imágenes del lenguaje y utilizarlas, pues están en el desierto, adonde hay que ir a buscarlas" (79). En cada una de estas, el poeta explora la técnica del poema encontrado. Mientras que en las secciones intermedias: el museo de la pobreza (21), lloicas en el abrevadero (39), un beso para papá (55) y simulando aprendí a ser verdadero (69), las condiciones de marginalidad y pobreza de los sujetos "subalternos" (quizá en una de

9 A partir de los planteamientos de Walter Mignolo (2007), aludo a la expresión "herencia colonial" para referir las políticas de exclusión que establecen prácticas de discriminación y racismo entre los grupos marginales, mestizos o subalternos de la sociedad. Prácticas que han persistido a lo largo del tiempo, y aún hoy, bajo distintas formas de dominación basadas, fundamentalmente, en la diferencia étnica y cultural. 
las otras acepciones del sujeto "monitor") del Chile post-transición, el simulacro y el travestismo lingüístico-sexual del andrógino, el exilio y la inscripción psicoanalítica de la "ley del padre".

La condición de marginalidad que marca la agencia política del sujeto contra natura de Silva encuentra en Matria un reducto expresivo para la performance, operando con radicalidad tanto la apropiación de la palabra como la recuperación de la frase hecha/escuchada y la reescritura por variación del enunciado. Por un lado, la performance del travestismo lingüístico actúa mediante la recuperación de textos que están fuera del texto; valga decir, por medio de la técnica del readymade, para construir un collage de voces en torno a una subjetividad de lo mínimo y lo precario. O, dicho con Nelly Richard, "el desecho neobarroco" en tanto que simbolización cultural trizada, donde solo quedan restos (huellas y vestigios), de un "paisaje rasgado por alguna dimensión de catástrofe que debe entonces trasladar sus verdades hacia los bordes más disgregados del saber y de la experiencia" (1998: 77-78).

En Matria, el sujeto recopila fragmentos de voces de la cultura popular, periférica y marginal en la que se reconoce, y frente a la que asume un sentido de pertenencia y comunidad minoritarios, por medio del cual testimonia el proceso del devenir mujer y travesti. Se trata de una operación que despersonaliza la figura del yo al tiempo que actúa como justificación del habla "menor" que utiliza el sujeto poético para nombrar su objeto de deseo: el andrógino; allí donde las voces "intencionalmente desnudas y expuestas en el fossalario de la noche" (75), revelan el "hecho mismo del travestismo" (Sarduy 1969) como un artificio que desmonta los mecanismos de representación simbólica del género para la construcción de una identidad biopolíticamente asignada (hombre o mujer). La contracción de fosa y salario, al cifrar la realidad política de la historia reciente en Chile (dictadura y transición), emplaza el "barroco del desecho" como metamorfosis de cuerpos que "atraen sobre su textura antisocial los efectos retóricos de una diseminación creativa de significados plurales" (Richard 89). He allí la diseminación creativa y la plurisignificación de "fossalario"; un término que convierte el residuo social (el travesti) en un excedente creativo y crítico.

Lo que resulta más relevante de estas operaciones en la poesía de Silva, y que se concreta como proyecto en la lectura de conjunto de sus tres poemarios, es la marginalidad sexualizada de los cuerpos 
biopolíticamente asignados como femeninos. Tratándose de cuerpos biológicos que aluden a una alteridad de esta naturaleza (la accidentalidad de un sexo femenino), como de cuerpos producidos artificialmente por la retórica y práctica del travestismo (como se deja leer, notablemente, en el apelativo "lloicas en el abrevadero"), y donde la figura del andrógino -que atraviesa los tres libros- sirve de ícono al desmembramiento de esta ficción normativa del género. Lo que Silva hace ver, entonces, con estas figuraciones estético-políticas del devenir mujer y travesti, es la vivencia sexual, periférica y marginal, de una serie de sujetos tachados por las biopolíticas de control del cuerpo y las identidades de género que imponen los sistemas de control sobre ellos, el diagnóstico clínico y familiar-social de la anomalía (Espinosa 2008). Pues no hay que olvidar, tal como enfatiza Giorgi, que los cuerpos contra natura han ofrecido desde siempre un mecanismo retórico capaz de contener y revelar sentidos políticos, históricos, culturales, alrededor de la imaginación y "los lenguajes del exterminio". Ellos exhiben la inscripción del cuerpo en el orden biopolítico cuando su existencia es inseparable de su función normalizadota, a la que contestan y politizan, pero de la que no se pueden escindir cuando esta le es constitutiva; "es su sedimento" (Giorgi 18).

Por otra parte, al preguntarse por el lugar de una voz, por una lengua, una indumentaria y una nación a la que no logra ajustarse, el sujeto poético de Silva interrogará cómo hablar, con qué lengua articular el intercambio simbólico y social de los hablantes, con qué alfabeto descifrar su otro (Berenguer). De allí que, tal como sucedía en Andrógino y Analfabeta, en Matria las voces semioticen en femenino (la travesti, la temporera, la india amancebada, la ñusta precolombina del amor, la india travestida de selva lírica), enfatizándose en ello la cosmética travesti y alegorizada de sus protagonistas, o, en otras palabras, del kitsch popular, lumpen y marginalde sus relatos:

Yo me compré un vestido lindo, pero lindo, cuando tenía catorce años, lo oculté por un año, como también yo, al año siguiente mi padre me exilió. Pero mis vestidos mis pinturas descoyaron en una quinta de recreo en Buin. Ahí conocí la vida antes yo estaba muerta.

La Gaby (Gabriel Ricardo) 
El jueves mataron a la Marión en la panamericana.

Un camionero jalao le puso dos tunazos en el cara, el culiao dice que le querían robar, pero está cagao. $\mathrm{Mi}$ primo es paco y yo ya le conté todo. Al funeral de la Marión no fue nadie de su familia, lloramos todas. En el ataúd le dejamos su más bello odio. Quizá mañana sea yo.

La muñeca (Luis Vidal) (75).

Algo parecido sucede en el poema "Beatitud" cuando la voz del hablante desaparece para dar lugar al discurso de otras voces, que ingresan al espacio de la página desde diversos ámbitos de la realidad social marginada. Se trata de cinco segmentos que asumen el formato de cartas de petición o de agradecimiento, en las que distintos sujetos femeninos, con su rúbrica, se dirigen a una animita, también femenina (Malvinita). El universo popular desposeído busca auxilio en ella a través del ruego, la oración, el acto de fe como la única posibilidad de salvación, resistencia o cambio. "Cartas halladas en un cementerio", dice la entrada del poema como acotación de la escena, en un afuera del texto marcado por la neutralidad del hablante. A lo que agrega: "Juana Iris no pudo evitar cleptómana comunión" (32). De modo que, si por un lado, vuelve a ser otro caso de poema encontrado, que marca la relación de los frentes arte-vida o escritura-realidad; por otro, determina su condición de objeto transformado e intervenido por la palabra y, en tanto que tal, de objeto performatizado o estetizado (Espinosa 2008), que anula el efecto de verdad-referencialidad aun cuando pudiera tratarse de una transcripción de esos materiales, supuestamente encontrados (pues todas las cartas están fechadas en septiembre de 2001). Estamos aquí ante una operación de montaje textual, donde la "cleptómana comunión", que une dos términos antagónicos, aparece como un guiño para llamar la atención respecto a la intervención del sujeto sobre el objeto que recrea o transcribe, las cartas, pero que en esta ocasión revela el melodrama cursi no de las travestis, sino del estereotipo de mujer cristiana, beata, que pide favores, sobre todo sentimentales, a la animita: 
Te escribo esta carta para decirte y darte un millón de gracias por el favor concedido ahora que estoy en el... Él se llama Juan Francisco Segundo Díaz León por favor se lo suplico de todo corazón que me quiera mucho y que nunca me deje sola ya no quiero sufrir de nuevo porque siempre pierdo yo. la quiero mucho

María Teresa A.Z. 15/09/01 (32-33).

La marginalidad social, étnica y sexual como expresión de un devenir minoritario pone en entredicho, así, las relaciones hetero-normativas de poder como un programa vital al tiempo que un proyecto político. La apuesta por el cruce de lenguas o por un programa intercultural que atienda a la permeabilidad y la porosidad del encuentro de fronteras de diversa naturaleza (étnicas, de género, geopolíticas, sociales y culturales), y el reconocimiento de la "diferencia", apela en Silva a la necesidad de un rito de iniciación al simulacro para la vida mutante -travesti, andrógina- de los sujetos invertidos o anómalos, que esta matria alberga en su territorio desposeído, violentado. De allí que el sujeto feminizado en la escritura de Silva se debata siempre entre varias lenguas de un sincretismo prehispánico para la definición de una gran comunidad americana:

Ramera Amancebada de sol Azteca

Ona Maya Zapoteca araucanita

Quechua Aimará Naguatl

De sangre mi vestido jamás americana $(10)^{10}$.

El verso, "de sangre mi vestido jamás americana", se repite tres veces en el espacio de toda una página, duplicándose la misma cantidad de veces y entre paréntesis, en su versión al inglés conforme una gramática oralizada y la dicción incorrecta de las palabras -spanglish y mala ortografía-, como si se tratara de un sujeto que desconoce la norma lingüística del inglés o de un sujeto aculturado (en el sentido de

10 Esa comunidad que en Analfabeta comenzaba a hacerse visible en el relato personal de la anomalía: "ramero fue mi nombre, el desorden mi guía/ -él amaba más, yo amaba mejor-/(...)/ ora levanto tu cadáver practico el arte de la putrefacción / (...)/ pájara muda pluma nocturna / flor mustia/ sánscrito quechua arameo/azufre fuego lluvia/sangre aún más horrible que el ojo de la vida/ clínica taco aguja" (48). 
asimilación a los patrones de la cultura o norma dominantes), en que se vuelve a hacer explícita su marca diferencial: "(mai drés in blod never américan)" (17). Se trata de una práctica asimétrica de bilingüismo, o de diglosia lingüístico-cultural que señala los comportamientos culturales políticamente relevantes en una situación de tipo colonial (Lienhard 1992). Por lo que la redundancia lingüística, más la incorrección del idioma, señalan, aquí, no solo un énfasis ideológico del texto, sino también la proliferación significante, hiperbólica, excedente del "desecho neobarroco" que simboliza su lengua "menor", aquella que desarrolla una minoría de origen social, étnico o sexual dentro de una lengua mayor o dominante, de acuerdo con una operación de desterritorialización del idioma, en que "todo" es político y en que "todo" adquiere un valor colectivo (Deleuze y Guattari 2001). Según esto, puede especularse que el verso, "de sangre mi vestido jamás americana", afirma por negación la modernidad/colonialidad del poder ${ }^{11}$ en tanto remite a una condición dada o, más bien, naturalizada en el imaginario geopolítico-cultural del sujeto que "habla" en su calidad de despatriado y que no es, por tanto, equivalente a un subalterno. Aquí el sujeto habla por "su" diferencia que es tan propia de su situación particular como del colectivo étnico, sexual y de clase que representa o quiere representar. Su propia alteridad, por ende, es representación de un yo colectivo, como escritura y discurso, de la otredad; valga decir, de las distintas voces y posiciones ideológicas que ingresan al texto en lugar de los grupos sociales diferenciados por su estrato o jerarquía, de acerado a su actuación en la esfera pública de la comunidad social que los margina y excluye.

El sujeto poético de Matria sabe y hace explícito ese saber: que una condición, si acaso étnica o racial como la sangre, no se corresponde con el imaginario cultural de la hegemonía americana. Esa sangre es mestiza, híbrida, indígena pero no dominante. En tal sentido, la perspectiva ideológica del texto refuerza la idea de que el "descubrimiento/

11 Con la expresión 'colonialidad del poder', Aníbal Quijano (2000) refiere el patrón de poder colonial que constituye la complejidad de los procesos de acumulación capitalista, articulados en una jerarquía racial/étnica global y sus clasificaciones derivativas de superior/inferior, desarrollo/ subdesarrollo, y pueblos civilizados/bárbaros. Mientras la noción de 'colonialidad' vincula el proceso de colonización de las Américas y la constitución de la economía-mundo capitalista como parte de un mismo proceso histórico iniciado en el siglo XVI, pero que se mantiene hasta nuestros días (Castro-Gómez y Grosfoguel 2007). 
invención de América"12 es el componente colonial de la modernidad. Modernidad/colonialidad que Silva encara desde la mirada del despatriado y la "herencia colonial" que implica entender y asumir esa diferencia desde la diferencia misma como un sujeto marginal antes que un subalterno, impedido o imposibilitado de habla, de tener una voz propia o de articular un discurso como auto-representación y representación colectiva de un devenir minoritario. Así lo expresa el primero de los poemas de Analfabeta que puede leerse como el primer manifiesto del proyecto estético-político de Matria:

Estuve sentada en mi lengua por siglos

ora despierto para la antinatural América

voy con sonido de Cuzco, Mazatlán, Fuego de la tierra

Ataviada de neones; artificio de jardín para la analfabeta

¡Ah que mi vulva es rubia rabia, goteo de caverna!

(...)

¡Ah, qué canto de la mordaza! (Analfabeta 13).

El poema enfatiza la condición del femenino travesti como marca de ese proceso de "violencia simbólica" que construye el propio sistema discursivo del poemario, y la "violencia sistémica"13 de los procesos de mestizaje y aculturación que padece el sujeto marginal desde su condición étnica y de género, mujer e indígena:

Mi Ñusta castra el parloteo de cristianos que no

Poseen memoria (...)

Mi sexo se traduce a monosílabos

a un trompe indagando en la memoria de tu sonido (...)

Soy lengua diezmada -toda España en mis hombros- (Analfabeta 17-18).

12 Para Walter Mignolo, la idea de "invención" y no "descubrimiento" de América, es una puerta de entrada a la decolonización del saber: "si descubrimiento es una interpretación imperial, invención (...) es un intento por decolonizar el saber imperial (...) Lo que tenemos aquí son dos interpretaciones, una que brinda la visión imperial y otra que propone la visión decolonial. Ambas coexisten en dos paradigmas distintos. El imperial sostiene e impone la visión dominante (...) El paradigma decolonial lucha por fomentar la divulgación de otra interpretación que pone sobre el tapete una visión silenciada de los acontecimientos, y también muestra los límites de una ideología imperial que se presenta como la verdadera (y única) interpretación de esos mismos hechos" (57).

13 Utilizo las categorías de Slavoj Zizek (2009), de "violencia sistémica", como aquella que refiere a las consecuencias del funcionamiento de los sistemas económico y político, y, por lo tanto, a la violencia inherente a las condiciones del capitalismo global. Y "violencia simbólica", como aquella aplicada al uso y las formas del lenguaje, que determinan la imposición de cierto universo de sentido y representación de la memoria y experiencia de los sujetos excluidos o subalternos. 
La imagen movediza, fluida y fluctuante, del sujeto travesti que no es él ni ella, que no es uno sino todos en el marco que define una colectividad periférica y marginal, permea la visión de la ciudad y la patria que no es enteramentemasculina, puesto que también se ha travestidoy desplazado, intercambiando sus signos estables por los significantes rebeldes de aquello que aparenta ser pero no es (la matria de los desposeídos). Pues tal como señala Fanny Arango-Keeth sobre Vallejo, en Silva es posible advertir una poética de la "resistencia" en la feminidad metafórica de sus hablantes cuando el poeta asigna una identidad femenina a la representación simbólica de un país, sustituyendo el paradigma de patria por el de matria "cuyo valor connotativo femenino se relaciona con la práctica sociohistórica del sujeto femenino" (84). Y así como la matria española de Vallejo en España aparta de mí este cáliz tiene un objetivo ideológico, la Matria de Silva también, al generar un descentramiento del estado patriarcal como cuerpo político para sustituirlo por un cuerpo materno "que da vida y alberga al sujeto colectivo (...) como centro y recinto de su memoria social" (87). Para Zurita, en la obra de Silva ese cuerpo-ciudad-patria va a existir únicamente porque revela "la profunda conflagración de un idioma que no ha alcanzado la paz con sus hablantes" (2008), y que, por lo mismo, no puede sino transformarlo todo (un continente, un país, un barrio) en margen, periferia. Periferia que en Silva, como así también en varios otros de los náufragos del 90, se instala en el horizonte de la globalización y el capitalismo mundial, de cara a las consecuencias políticas del periodo de la post-transición en Chile.

Como metáfora de un cuerpo-ciudad-nación violentado, conquistado, colonizado, una de las secciones más abiertamente ideológicas de Matria, "el museo de la pobreza", y el primer poema de la serie, "Bungalow", enunciará por defecto y a través de una ironía lo que no es la figura simbólica de la casa al contradecir su acepción de uso corriente: la acogedora cabaña de madera remitirá, aquí, a la mediagua poblacional de los sectores periféricos de la ciudad, donde las "geometrías del sueño" de la casa propia chocan con la situación de precariedad que simboliza la figura material de una casa misérrima, la casa del SERVIU. De modo que los sueños de sus pobladores son en realidad las formas sentimentales y afectivas que proyectará, dentro de esta casa, la cultura mass mediática de la televisión sobre el sujeto marginal que, mediante el culto de las 
figuras del pop y el melodrama kitsch de las teleseries mexicanas ${ }^{14}$, va a desarrollar una fantasía compensatoria por la falta de igualdad y justicia sociales en el acceso digno a la vivienda:

AQUÍ LOS RESTOS

PARADA EN CUATRO TABLAS

DE CUATRO BOCAS CUATRO

QUE PREFIGURAN UNA CASA

UNA MEMORIA

CARDUMEN DE CHOZAS

ENDEUDADAS HASTA EL BRASERO DEL ALMA

DIGNOS PERO DIGNOS (23).

En "Bungalow", la realidad social es clara: hambre, hacinamiento, deuda, que padece no solo el sujeto periférico, el marginal, el subalterno, que es siempre femenino: mujer, travesti, obrera, campesina, analfabeta, sino también una amplia mayoría de población civil en la sociedad chilena actual. Por lo que el deíctico "aquí" sitúa la espacio-temporalidad de un Santiago próximo y real: antes que la comunidad imaginada el territorio geopolítico que los excluye, el Chile de la post-transición que descuella por las condiciones neoliberales (léase, políticas públicas) que enfrentan desde la precariedad los estratos sociales más desfavorecidos del país:

\section{SERVIU ES LA CATEDRAL DE MIS HERMANAS}

\section{LA TELESERIE}

\section{LA EXTENSA GEOMETRÍA DE UN SUEÑO}

TAN ORGULLOSA

LA COCINA $2 X 1$

14 Lo que se observa en este poema de Silva puede extrapolarse a la situación generacional de los náufragos del 90, que bien describe Francisca Lange en el prólogo a Diecinueve (poetas chilenos de los 90): "los poetas de los noventa se instalan provistos de un peculiar discurso articulado en una época donde el adoctrinamiento masivo se realiza por medio de la televisión: la creación de un showbusiness que pretendía homogeneizar la percepción del mundo chileno, la perversa selección literaria de los programas oficiales de educación y la escasa y centralizada oferta cinematográfica y musical ocuparon un lugar destacado" (20). 


\section{LA PIEZA SE SANDRITA 2X2}

2X3 EL LIVING COMEDOR

LA MARQUEZA ME CABE JUSTO EN 3X2

EL BAÑO $1 X 1$ ¡Y CON TAZA DE LOZA!

EL PAISAJE LO PINTÉ EN EL CALLAMPERÍO

LA CASA; MI BELLA Y FUGAZ ESTADÍA

SERVIU ES LA CATEDRAL DE MIS

/ HERMANAS (23-4).

Las geometrías del sueño de la casa propia en el Chile actual se reducen a la choza, la callampa, la mediagua poblacional, de material ligero y de unas dimensionas tan estrechas, que por hacinamiento someten la vida de sus pobladores a unas condiciones infrahumanas. Con marcado humor negro, el poema ironiza estas condiciones al decir que SERVIU es la "catedral de mis hermanas" y que el baño, como el gran privilegio, tiene "taza de loza" (24). El servicio de vivienda y urbanismo, creado en el 1976 por el Ministerio de Vivienda y Urbanismo, es la única casa donde se materializan los sueños de la campesina, la temporera, la indígena. SERVIU es una figura de la patria, "un río de sangre", como reza el epígrafe de Estela Díaz Varín en el poema "Una patria" de Silva, y, en tanto que tal, representación de una de las tantas "microdictaduras democráticas" (Hernández 2008) que bajo el tamiz de las biopolíticas de control e higienización ha impuesto el sistema neoliberal de políticas públicas en Chile. Esa patria que recuerda el lugar del nacimiento, "San Bernardo mi odio; mi antigua patria/nunca sali de tu horror" (68), y que condena al sujeto a ser una "ruina de aromas y amores $/(\ldots) /$ una india violentada por una ciudad de balcones y / alamedas" (66).

En uno de los fragmentos en que se divide el poema "Temporera", encontramos la voz de una mujer parturienta, cuya pobreza material la hace asumir todo el castigo social de quien se sabe condenado por el determinismo que impone esta condición de miseria y precariedad: 
AL FONDO MI GRITO DE LAS NALGAS DE LA

/TIERRA YERBAMOTO RUDA PALTO

JARDÍN DE PÚAS YO MARÍA LEVITANDO SIN /

CALZÓN

SIN AMOR LA MIRADA FIJA EN UN ORGASMO

LA CASA TIEMBLA VACA PATE'VACA MARACA

/ LACHA SUELTA

RAMERA AMANCEBADA TEMPORERA

EL INCENDIO EL AMOR SE TE FUE

YO LA MUERTA LA MESERA LA MAMONA LA

/ CARA PARTIDA (26).

El énfasis de las letras mayúsculas y remarcadas en negrita destaca las expresiones que profieren esta condena, de acuerdo con la doble falta del sujeto periférico: su condición social de pobreza (temporera) y moral de prostituta (ramera, amancebada). Lo que explica el despliegue de insultos que en jerga popular recaen sobre su anomalía: "pate'vaca", "maraca", "lacha", "suelta". Faltas que, no obstante, el sujeto asimila aunque en un tono menor o bajándole el perfil del garabato gratuito y fácil en el momento de autorreferirse: "yo la muerta, la mesera, la mamona, la cara partida" (26) ${ }^{15}$. La enumeración va amplificando dichas condiciones, hasta que, el final del poema, la voz cede el lugar del habla a su alter ego invertido, su otro yo puesto en cuestión y mostración, la temporera travesti que aparece enmarcada en el discurso por el uso de las comillas:

“Soy María Jorquera Melenao pertenezco a esa ralea de mujeres en las cuales se deposita toda la animadversión de una moral rudimentaria, sostenida en el ejercicio de lapidación y exilio de la concubina" (27).

15 En el poema "Taxi" de Analfabeta, la hablante, con similar tono, confesaba: "yo la sarnosa / la polvorienta la carita partida / (...)/ llevo el mejor trozo de carne / en esta pellejería" (35). 
El sujeto mujer/travesti admite su pertenencia a esa "ralea" de mujeres prostitutas -con cierta nostalgia: "una casta en desintegración total" (25)-, asumiendo las causas por las cuales es objeto de exclusión y lapidación. Porque la Matria de Silva es la patria de los sin patria, los que primero son expulsados por la sentencia-anatema que emiten los padres contra el hijo "raro". Los padres, y desde allí la indumentaria material y simbólica que sirve de uso y práctica para el aprendizaje social del género: "mi enagua", el vestido que es objeto visible de la identidad sexual, y "mi lengua", aquella que se adquiere de forma pasiva y acrítica (y por tanto, violenta) como transmisión de la herencia obligada que conduce a la dictadura del nombre, al hablar como si, "me llamo María Jorquera Menelao": "LA LOCA LA PASCUALA LA MENOR / LA DIEZMADA" $(28)^{16}$.

Finaliza el poema con la transcripción de una segunda voz, que no es la de María Jorquera, sino una voz neutra, externa al discurso del personaje, pero que reitera y confirma la visión del anatema social del cual ha sido víctima. Se trata de la canción infantil "La niña María", que todas hemos aprendido en la escuela primaria por la pedagogía del género. Porque es a la niña a quien se obliga a bailar y a quien se castiga si no lo hace ${ }^{17}$ :

\section{LA NIÑA MARÍA HA SALIDO AL BAILE}

BAILE QUE BAILE QUE BAILE

Y SI NO LO BAILA CASTIGO LE DARÁN (25-8).

16 Algo que también era motivo de especulación en el poema "Lar" de Analfabeta, que desde el sentido invertido del topónimo "lar" -lugar de afecto y protección, el hogar, la comunidad y la familia-, apelaba a su sentido opuesto, la casa desprotegida y sin resguardo del sujeto despatriado: "La casa está cargada/Los gritos de tu madre se confunden con el hambre de críos/que practican el fracaso de sus vidas; la futura amnesia/de las crines del sol/La huella del horror en cortinas vasos puertas/-el invierno se quedó a vivir en esta casa-/Maquillaje para la tísica/amor y odio en el tendido eléctrico de una plaza/-tal vez mi único hogar-/Degenero" ("LAR" 23).

17 Situación que también aparece tematizada en Analfabeta cuando el sujeto invierte el enunciado del título de la canción que remite al nombre de la niña, "La niña María", por el acto de muerte que representa esa imposición del baile: "La niña Moría": “Alguien traza cruces cuando ebria me alejo del amor / Y si no lo bailo / Castigo me darán / Desnuda discoteque mi cristal / Destello tras destello algo parecido a todo el dolor / Y si no lo bailo / Castigo me darán" (Analfabeta 26) 


\section{El devenir mujer y travesti para otras figuraciones del margen}

La loca y travesti de Matria, como las dos grandes figuras masculinas del "gay" exageradamente afeminado y cursi, caricaturesco, pinta los Andes de rosa (en algún momento será Miss Andes), viste con los atuendos de la madre, y en esa visión de la india que lleva dentro practica la lengua mapuñol, "lengua sitiada, quebrada entre la memoria de su propia violencia y el impulso del placer" (Zurita 2008). El texto va elaborando una performance lingüística que prolifera en el desvío de las identidades de género interrogadas por las figuraciones del travestismo: hombre/mujer; patria/matria, de acuerdo con una escritura neobarroca que no teme el rebuscamiento, la cursilería y el desborde en la construcción de un texto estético y político, que tiene una función ética de representación al tiempo que performativa de teatralización o espectacularización desmesurada (Espinosa 2008). Esto es lo que sugiere el verso, "simulando aprendí a ser verdadero", que abre la última sección del poemario con "La vida subjetiva", en que la voz posicionada del sujeto en lo precario y marginal, reactiva la conciencia trágica de habitar un cuerpo que no se sabe natural o propio (como la lengua, la identidad), y que impone, contra toda voluntad, ciertas prácticas de comportamiento sexual: "penetrar y ser penetrado -digo-/es la ley del universo.../" (36). "La vida subjetiva" es tanto el relato de una determinante histórica, política, como la fractura de una memoria personal, aquella que quiere dejar testimonio de un proceso de transformación que ha ocurrido en un plano temporal y que, por tanto, se puede situar en el tiempo: "cuando eras un hombre", aun se trate de un pasado inexacto y un tiempo presente no concluido del todo, pero que señala el proceso del devenir de acuerdo con un acto de simulación en que el sujeto aparenta ser lo que no es, pero que, como añoranza o anhelo, corre el tupido velo de aquello que se oculta bajo el disfraz. Por eso no es casual que este acto convoque no solo a los huérfanos, despatriados, sino también a la figura mutante de la novela de Balzac, Serafitus-Serafita, el ser máximo, superior cuando encarna a los dos sexos a la vez en tanto signo de una totalidad originaria, del hombre primordial, antepasado mítico de la humanidad ${ }^{18}$ :

18 En el poema "Dos escrituras", este ser divino, el andrógino como ser superior, enfatiza la complejidad sexual del sujeto poético de Silva: “(...) Cruzado e invertido en el goteo de tu miembro / Ave del paraíso amó cuanto quiso en espejo salino / en el rizo resonante de un amor. / Mitad varón mitad hembra / De sol la cabeza de luna las vértebras" (52). 
Cuando eras un hombre el sol era un punto amarillo, una ampolleta de fonda en sus córneas de vidrio $Y$ la luna un disfraz menor para cantarle a huérfanos y Serafitus (...)

Una tarde me encontré con la vida Y le arranqué sus aros de campesina china Diseñé unos ojos para contemplar

la nueva vihda (73).

Después de la paráfrasis de Rimbaud -“Una noche, senté a la Belleza en mis rodillas. -Y la encontré amarga. -Y la injurié" (Une saison dans l'enfer)-, el verso final, "la nueva vihda", además de la alusión al Zurita de la Nueva vida, corresponde a un verso reescrito de un poema de Andrógino: "toda enfermedad se transmite con la sangre" (21), y también a un recurso de aliteración/variación de uno de los Koan que elabora Silva en el poema homónimo de Matria: "en la sangre, ese suave dulzor de la VIHDA" (76), que en Andrógino tematizaba la realidad de un "Trance" hacia el deterioro y la pérdida:

Toda enfermedad

se transmite con la sangre

ya no recuerdo

la delicada lluvia de abril

ni aquellos trances solitarios

por los caminos del bosque

todo fue en anomia

como lo cantan los desesperados

No recuerdo

cuando comenzó el deterioro ("Trance" 21).

Una vida que marca con esta intromisión consciente de una letra que se ve pero no escucha, la h, el doble sentido que ella representa: una vida nueva que no es perceptible para "los seres simples y vulgares, los heterosexuales" (88); una vida marcada por el estigma de la muerte, la 
enfermedad y sus metáforas, del "capitalismo tardío" (el sida); el paso de una vida "normal" a una vihda "anómala". El grafema h es aquí una de las formas fracturadas o dislocadas de asumir la voz, tal como propone Magda Sepúlveda para el joven sordomudo de [Guión], de Héctor Hernández, $H$. Sobre esto, nos dice la crítica:

En el camino de la memoria y del olvido, la voz debe trazar otro guión para su subjetividad y para ello es necesario reflexionar sobre el alfabeto aprendido. En esta línea, la voz va poetizando sobre la relación entre ciertas letras y su cuerpo. Por ejemplo, $\mathrm{H}$ es la letra del nombre y del apellido del autor, Héctor Hernández, cuya sigla HH es usada también en el libro. $\mathrm{H}$ es, además la letra muda y, como tal, el nombre del niño sordomudo H. Asimismo $\mathrm{H}$ es la inicial de homosexual. Por tanto la opción por esta letra es un significante motivado por alusiones múltiples, todas ellas vinculadas al imbunchamiento de lo propio $(249)^{19}$.

Asimismo, Antonio Silva cifra en este poema, "La vida subjetiva", su marca de alteridad, remitiendo al grafema h como signo de una afasia o mudez añadida de forma suplementaria a la palabra y al sujeto mismo.

Finalmente, en su arte de la "manicure cosmética y pincelaje"(35), el sujeto reincide en la proclama del manifiesto en su poema "Los maricas", en el que se cumple con mayor énfasis esa "teatralización performativa" de la voz, cuando sintetiza en un gesto estético y político, su programa vital del hecho mismo del travestismo: la imagen autoconstruida de un personaje minoritario que deviene mujer y que aspira a la figuración del andrógino como ser perfecto -de allí la cita inicial de Eliade que antecede al poema: "El andrógino es considerado superior a ambos sexos / Porque encarna la totalidad y por lo tanto la perfección" (41)-. El marica de Silva no es un andrógino, sino su figuración, su estadio de realización

19 Sepúlveda remite a la figura mitológica de origen chilote y mapuche del imbunche, que en lengua mapudungun quiere decir "persona deforme". Entre sus características está la de no poder hablar. Como figura simbólica utilizada por algunos miembros de la promoción del 90, véase, por ejemplo, el poema "El imbunche" de Alejandra del Río: "Decido hacerme un maleficio/Cojo la plateada aguja ancestral/con ella hilvano el punto que hará costura mis ojos $/ \mathrm{mi}$ boca $/ \mathrm{mis}$ oídos $/ \mathrm{mi}$ sexo/ (...)/Cojo mi plateada aguja ancestral/para darme estatuto definitivo de engendro/!La costura me salvará de sus saqueos!/Escarben ahora bajo los parches lo que les pertenece/yo no podré verlos/Vociferen mi culpa hasta quedar vacíos/no los escucharé/Distingan entre los escombros las razones de su dolor/no abriré la boca en mi defensa/Vuelvan a jurar el amor que me tuvieron/ya no veo el tiempo/nada sentiré." (31-32). 
potencial, imaginada y proyectada en el deseo. Figuración que diseña la imagen espejística de un muchacho periférico que nació "para ser/ Contemplado, un Adonis alógeno/Y poblacional", conforme su "espureo talento de neón sudaca" (29).

El poema "Los maricas" refuerza la condición doblemente marginada del sujeto marica ${ }^{20}$, antes periférico y marginal; aquel que asume el homoerotismo en el desarrollo de diferentes estadios de constitución de una identidad a partir del cuerpo; insistiendo en las marcas, los gestos, los ritos que destacan la valía de sus "contactos intensos":

Cruzados en un parque

En el filamento de las sombras

Entre destierro y farol

Hacen su entrada coja los maricas

Las bestias de ágata, torcidos e inmundos

Tronchando con sus gestos

El decorado siempre bastardo de una ciudad felina

Los maricas y sus citas

De párpado en párpado, su lenguaje binario

Como polillas siempre atentos a una nueva antorcha

que surja en el vergel nocturno

Uno es la otra la otra es ella en mi y en el otro

Sus pequeños y violentos actos

Paridos en estertor de un circo pobre

En una luminaria se emborrachan los maricas

Y relatan siempre una misma historia

Despatriados los maricas levantan una bandera; un

pañolete izado

en la fetidez de la muelas

De la mano van los invertidos

$\mathrm{Al}$ encuentro de matarifes, lumpenaje y soldados

$\mathrm{Al}$ encuentro de mi canto

20 En Matria, el personaje travesti de Juana Iris (Jonathan Riquelme Menelao) da cuenta de su identidad "marica" cuando el sujeto-narrador se refiere a una canción: "Juana Iris en alcohólico trance recitaba a todos una pequeña canción de un desaparecido poeta "maricón es una palabra que inventó mi padre para burlar tu vida" (...) La Iris se detenía como una lechuza que, posada en el balcón de la noche, apretaba su pecho y su voz era otra" (44). 
Al encuentro de un plumaje abanical

Locos y tristes los maricas

Condenadamente alegres

Indeciblemente bellos, bellos. (41-2).

El marica, como antes el andrógino y la analfabeta, es la última simbolización de las minorías que explora Silva. La retórica programática de este poema-programa se lee en las varias menciones y adjetivaciones del vocativo "maricas": "torcidos", "invertidos", "inmundos", "polillas", "despatriados", "bestias de ágata", "su lenguaje binario", "su plumaje abanical", "locos", "tristes", "alegres", "bellos". Nótese, no obstante, que la aproximación al otro, pero también a sí mismo, se produce por inversión y, a su vez, fusión de la mirada. El que mira es a su vez lo mirado, lo otro, lo diferente. Uno es la otra. La otra es ella en mí y en el otro. Ese otro que es en realidad otra; un hombre/mujer (o a la inversa) que se nombra en el plural "ellos", en una fórmula inclusiva e incluyente que avanza hacia el nosotros colectivo, desterritorializado y político de los devenires minoritarios; allí donde la hegemonía se ve arrostrada por las voces de la otredad: mujeres, prostitutas, indígenas, travestis, transexuales... allí donde es posible la emergencia de otra comunidad potencial, de otra conciencia y otra sensibilidad cultural. 


\section{Bibliografía}

Arango-Keeth, Fanny. "La construcción figurativa de la matria y del sujeto español en España, aparta de mí este cáliz de César Vallejo". Encuentros de viejos y nuevos mundos. La literatura hispánica vista en el 2002. Eds. Enrique Herrera y Cecilia Moreano. Lima, Perú: Asociación de Estudios Culturales Hispánicos, 2003.

Bello, Javier. "Los náufragos". Los naúfragos (1998): s.p. Web. 14 Abr. 2014.

Castro Gómez, Santiago y Ramón Grosfoguel (eds.). El giro decolonial. Reflexiones para una diversidad epistémica más allá del capitalismo global.

Deleuze, Gilles y Félix Guattari. Kafka por una literatura menor. 1975. Trad. Jorge Aguilar Mora. México: ERA, 2001. . Mil mesetas. 1980. Trad. José Vázquez. Valencia: Pretextos, 2010.

Del Río, Alejandra. Material mente diario. Santiago de Chile: Cuarto Propio, 2009.

Espinosa, Patricia. "Matria, de Antonio Silva". LetrasS5.com (2008): s.p. Web. 9 Oct. 2013.

___. “La poesía chilena en el periodo 1987-2005”. Crítica Hispánica XXVIII (2006): 53-65.

Garabano, Sandra. "Lemebel: políticas de consenso, masculinidad y travestismo", Chasqui. Revista de literatura latinoamericana 1 (2003). 47-55.

Giorgi, Gabriel. Sueños de exterminio. Homosexualidad y representación en la literatura argentina contemporánea. Rosario: Beatriz Viterbo, 2004.

Hernández, Héctor. "Anomalía y bestiario para el ojo neoliberal". LetrasS5.com (2008): s.p. Web. 9 Oct. 2013.

Jiménez, Verónica. Nada tiene que ver el amor con el amor. Santiago de Chile: Piedra de sol, 2011. 
Lange, Francisca. Diecinueve (Poetas chilenos de los noventa). Santiago de Chile: J.C. Sáez Editor, 2006.

Lienhard, Martín. “De mestizajes, heterogeneidades, hibridismos y otras quimeras". Asedios a la heterogeneidad cultural. Libro de homenaje a Antonio Cornejo Polar. Eds. José Antonio Mazzotti y Juan Zevallos. Filadelfia: Asociación internacional de peruanistas, 1996. 57-80.

López, Berta. "Tengo miedo torero, de Pedro Lemebel: ruptura y testimonio". Estudios Filológicos 40 (2005): 121-129.

Mignolo, Walter. La idea de América Latina. La herida colonial y la opción decolonial. 2005. Trad. Silvia Jawerbaum y Julieta Barba. Barcelona: Gedisa, 2007.

Mistral, Gabriela. Antología poética. Santiago de Chile: Universitaria, 2001.

Nómez, Naín. "Treinta y cinco años de poesía chilena: de la expulsión al naufragio en la ciudad fantasma". Poesía y diversidades. Lecturas críticas en el bicentenario. Eds. Megumi Andrade et. al. Santiago de Chile: Universidad de Chile, 2012.

Perlongher, Néstor. "Los devenires minoritarios". Prosa plebeya. Ensayos 1980-1992. Buenos Aires: Colihue, 1997. 65-75.

Quijano, Aníbal. "Colonialidad del poder, eurocentrismo y América Latina". Comp. Edgardo Lander. La colonialidad del saber. Eurocentrismo y ciencias sociales. Perspectivas latinoamericanas. Buenos Aires: CLACSO, 2000. 201-246.

Richard, Nelly. Residuos y metáforas (ensayos de crítica cultural sobre el Chile de la Transición). Santiago de Chile: Cuarto Propio, 1998.

Rosa, Nicolás. Artefacto. Rosario: Beatriz Viterbo, 1992.

Sarduy, Severo. Escrito sobre un cuerpo. Buenos Aires: Sudamericana, 1969.

Sepúlveda, Magda. Ciudad quiltra. Poesía chilena (1973-2013). Santiago de Chile: Cuarto Propio, 2013. 
Silva, Antonio. Matria, Santiago de Chile: Cuarto Propio, 2007. . Analfabeta. Santiago de Chile: Cuarto Propio, 2000.

_._. Andrógino. Santiago de Chile: Concurso Eusebio Lillo, Municipalidad de El Bosque, 1996.

?i?ek, Slavoj. Sobre la violencia. Seis reflexiones marginales. 2008. Trad. Antonio Antón Fernández. Buenos Aires: Paidós, 2009.

Zurita, Raúl. “El sol negro de Matria”. LetrasS5.com (2008): s.p. Web. 9 Oct. 2013. 